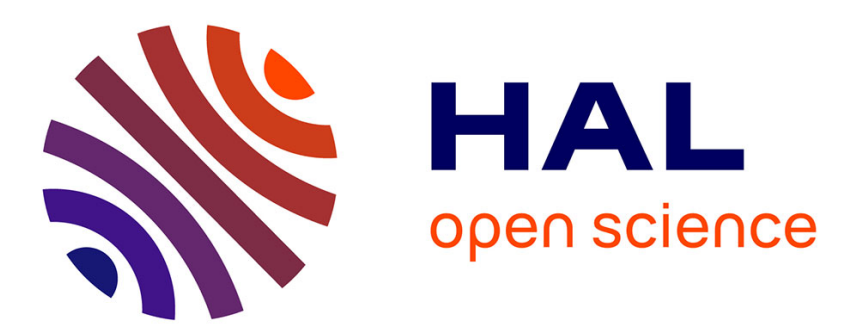

\title{
Feedback of the empirical approach to design the room and pillar mines. Application on chalk mines (France) \\ Marwan Al Heib
}

\section{To cite this version:}

Marwan Al Heib. Feedback of the empirical approach to design the room and pillar mines. Application on chalk mines (France). International Symposium of ISRM "Rock Mechanics and Rock Engineering: From the Past to the Future" (EUROCK 2016), Aug 2016, Urgup (Cappadoce), Turkey. pp.689-694. ineris-01854306

\section{HAL Id: ineris-01854306 \\ https://hal-ineris.archives-ouvertes.fr/ineris-01854306}

Submitted on 4 Sep 2018

HAL is a multi-disciplinary open access archive for the deposit and dissemination of scientific research documents, whether they are published or not. The documents may come from teaching and research institutions in France or abroad, or from public or private research centers.
L'archive ouverte pluridisciplinaire HAL, est destinée au dépôt et à la diffusion de documents scientifiques de niveau recherche, publiés ou non, émanant des établissements d'enseignement et de recherche français ou étrangers, des laboratoires publics ou privés. 


\title{
Feedback of the empirical approach to design the room and pillar mines - Application on chalk mines (France)
}

\author{
M. Al Heib \\ Institut National de l'Environnement Industriel et des Risques, Nancy, France
}

\begin{abstract}
The goal of this study is to improve the analysis of the stability of pillars and to answer the question of the choice of the pillar strength using an empirical approach. The pillar strength depends mainly on two factors: the uniaxial compression strength and the pillar geometry. We have shown in this study the importance of geometry of pillars by comparing calculations with and without the effect of $\mathrm{W} / \mathrm{H}$ ratio (slenderness). The sensitivity of the parametric study based on the empirical relationships converges to the same resistance of the pillar despite the difference between the coefficients of these empirical relationships. The methodology was applied to case studies (France). The application of these relationships can help to explain the collapse of Clamart mine (Paris). Generally, and in the absence of data, it will certainly be more prudent to use the relationships available taking into account the effect of uncertainty.
\end{abstract}

\section{INTRODUCTION}

The room and pillar mining method is conventionally used for shallow mines. The method consists in practice to create rooms separated by small parts of the deposit, deliberately not exploited (pillars). The depth is controlled by the deposit; the extraction ratio should be selected according the bearing capacity of pillars. The pillar function is to ensure local and overall stability of the surface and underground mine. The stability of mines should be checked for short-term, long-term, local (isolated pillar) and large scale.

Several methods (approaches) are used to design the pillars, from the simplest to the most sophisticated one. The design is generally based on empirical methods from lessons learned, sometimes with dramatic consequences due to large collapse. Geologists and engineers nowadays have more scientific approaches to assess the stability of these structures. They are based on analytical and numerical calculations, sometimes in $3 \mathrm{D}$ and use sophisticated models with numerous parameters used to evaluate the short and long term pillar behavior.

All approaches should assess the risk through a comparison between the stress of the pillar and strength. The simplest analytical approach is often preferred. It is enriched by the feedback. The design of the pillars passes by estimating the average stress on the vertical pillar and comparing it with the strength of the pillar. The safety factor corresponds to the ratio of the resistance of the pillar ( $\mathrm{Rp})$ with respect to the stress of the pillar $(\sigma \mathrm{p})$.

$$
S F=\frac{R_{p}}{\sigma}
$$

It requires great care in the choice of parameter to be taken into account to establish the design and the fair and accurate diagnosis based on uncertainties of underground conditions. Moreover, the choice of safety factor should take into account the presence of discontinuities, age etc. In case we retain a safety factor near one, the failure probability could increase significantly. The choice of an optimum safety factor value depends on the experience and extensive knowledge of the studied area.

The risk of instability faced by room and pillar mining method has different shapes and match a variety of failure mechanisms. The historical accidents in underground mines are often associated with the failure of the pillars (ex. Coalbrook collapse in South Africa, Clamart in France, etc.). The failure of the pillars is due to:

- the mechanical properties due to an insufficient intrinsic compression resistance;

- the buckling of the pillars becoming too slender or such as a result of roof falls;

- the geological structural and discontinuities may affect isolated pillars or whole districts of the mine;

- the exogenous factors can significantly reduce the resistance, it is primarily water and time.

Sudden collapses risk increases with increasing height pillar relative to its width (Mark, 2006).

In this paper, we will discuss the empirical relationship to estimate the safety factor of room and pillar mining method.

\section{PILLAR VERTICAL STRESS}

The excavation of the chambers changes the state of initial stresses in the massive and transfer the initial stress to the pillars. The pillar stress can be calculated 
using an analytical method to estimate the average vertical stress on the pillars: it depends on the depth of the pillar (h), density of the rock mass $(\rho)$ and extraction ratio $(\mathrm{E}), \mathrm{g}$ gravity acceleration

$\sigma_{p}=\frac{\rho g h}{1-E}$

This approach gives the average vertical stress and it does not inform about the spatial variation of this vertical stress through the pillar section and the other components of the stress tensor. The method may be used to estimate the stresses in the pillars of operating at several mine levels, mainly when the pillars are perfectly superimposed. Indeed, if the pillars are poorly superimposed and if the thickness of the parting bed is insufficient, the approach of tributary area cannot be used to estimate the vertical pillar stress and the state of stability.

\section{PILLAR STRENGTH}

The strength and behavior of the pillar is often linked to the behavior of specimens tested in the laboratory. Pillar strength is characterized from the uniaxial compressive strength $(\mathrm{Rc})$ of the rock determined by a uniaxial compression test on a sufficient number of samples. Pillar resistance is also related to the geometric shape and the slenderness of the pillar $(\mathrm{W} / \mathrm{H})$ : width (W) and height $(\mathrm{H})$. Based on these parameters, several empirical equations have been proposed to estimate the relationship between the issue value of uniaxial compression tests in laboratory $\mathrm{R}_{c}$ and the pillar strength of $\mathrm{R}_{p}$. The most general form of the equation is a mathematical power function.

$R_{p}=\lambda R_{c} \frac{W^{\alpha}}{H^{\beta}}$

$\lambda, \alpha$ and $\beta$ are numerical constants, they are determined through feedback and in-situ observations of the behavior of the stable and collapsed pillars. The first known relation was established after the disaster in the Coalbrook Coal Mine (South Africa), in which more than 900 pillars were collapsed and the loss of 437 lives. The relation takes into account the effect of scale and heterogeneity of the massif. Table 1 provides the values of these coefficients available in bibliographic references for different rock types (coal, limestone, etc.). Salamon and Munro (1967) have proposed coal pillar design relation from more than 125 historical cases. Hedley and Grant (1972), have shown that the equation proposed by Salmon and Munro can also be used for hard rock, checked for mines of quartzite with a uniaxial compression strength of $230 \mathrm{MPa}$. The analysis was conducted on an area of 60 pillars out of which 23 were collapsed. Esterhuizen et al. (2007) and others have established a relation for limestone mines. Their approach takes into account the conditions of the pillars, the state of the rock mass

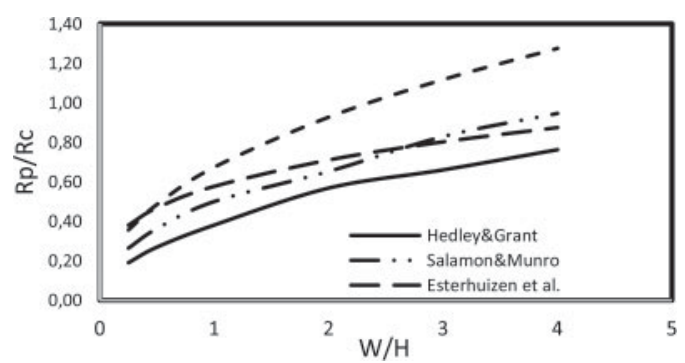

Figure 1. Evolution of pillar strength (Rp)-uniaxial compression strength $(\mathrm{Rc})$ against $\mathrm{W} / \mathrm{H}$ ratio according to different empirical approaches (see table 1).

fracturing. They proposed a sizing equation from thousands of stable pillars observed. Martin and Maybee (2000) used the Hoek-Brown criterion to study the stability of pillar and to take into account the effect of the pillar dimension and the width-to-height ratio.

It is noted that the influence of $\lambda$ (related to uniaxial compression strength $\mathrm{Rc}$ ) is considered linear, however the influence of the pillar geometry follows power function. Bieniawski (1968) noted that scale effect is a power function, the strength decreases with the increasing of the sample dimensions. Spanish iron compression strength was determined in laboratory, for different height/diameter ratio (H/D), ranged from 5 to 0.5 . The strength follows a power function comparable to those proposed for estimating the strength of the pillar (Oyanguren and Lain, 2003).

Based on the parameters of the Table 1, Figure 1 shows the evolution of pillar strength/compressive strength ratio $(\mathrm{Rp} / \mathrm{Rc})$ for different values of slenderness ( $\mathrm{H}$ is assumed to be constant and equal to $5 \mathrm{~m}$ ). At first glance of the coefficients $(\alpha, \beta$ and $\lambda)$ are all different because they have been established for different rocks. Nevertheless, we note that the results are close when $\mathrm{W} / \mathrm{H}$ ratio is lower than 0.5 or smaller width of pillars (or tall). On the other hand, the gap is widening after this value. We compare the previous results with the effect of scale with the following values $(\alpha=1$, $\beta=1$ and $\lambda=0.93$ ).

It is clear that the equations take into account in-directly the effects of confining and buckling associated with the geometry of the pillar. Note that most low slenderness $(\mathrm{W} / \mathrm{H}>>1)$, more horizontal confining stress in the pillar is important. The increase in the horizontal stress tends to increase the capacity of the pillar supporting the vertical load, which results in a reduction of buckling failure mechanism.

$\mathrm{Rp}$ pillar strength must be greater than the pillar stress, taking into account indirectly the geotechnical and geometrical parameters related to pillar design.

The use of a three of four equations can be conceded as acceptable in first step of the analysis (Table 1), especially for configurations and rocks with similar characteristics. One could even make the calculation for the three hypotheses (Salamon and Munro, 1968, Herdley et al. 1972, and Esterhuizen et al. 2011) and consider the average value. 
Table 1. Different parameter values to estimate the pillar strength.

\begin{tabular}{lllll}
\hline Reference & Rock type & $\alpha$ & $\beta$ & $\lambda$ \\
\hline Salamon and Munro (1967) & Coal & 0,46 & 0,66 & 0,93 \\
Hedley et Grant (1972) & Quartzite & 0,5 & 0,75 & 0,57 \\
Von Kimmelmann et al. (1984) & Sedimentary rock & 0,46 & 0,66 & 0,69 \\
Esterhuizen et al. (2011) & Limestone & 0,3 & 0,59 & 0,92 \\
W/H effect only & & 1 & 1 & 0,93 \\
\hline
\end{tabular}

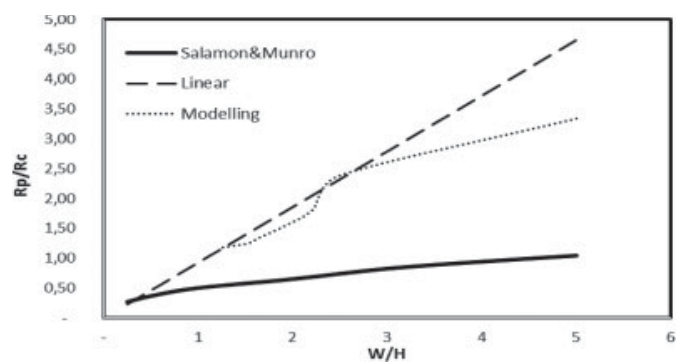

Figure 2. Evolution of pillar strength to the uniaxial compression strength for different values of $\mathrm{W}$-to-H ratio and different empirical equations and numerical modelling.

\subsection{Discussion and comparison}

Numerical methods are very useful tools to understand complex rock and structure behavior. Laouafa (2004) considered that the method of the tributary area ignores friction action between the immediate roof and pillar. The strength of the pillar increases because of friction forces between the immediate roof and pillar. He introduced a coefficient $\mathrm{Cp}$ of a variable value according to the pillar geometry and the mechanical properties of the mine layer (width, height, friction angle, cohesion). Laouafa carried out a simple numerical model to determine the evolution of the reduction/increased coefficient based on the pillar slenderness. The effect of the geomechanical properties (cohesion, friction) are well below the effect of pillar geometry. For pillars with $(\mathrm{W} / \mathrm{H})$ higher than 3 , the pillar strength can reach three times the uniaxial compression strength. For $(\mathrm{W} / \mathrm{H})$ very low, the pillar strength is equals to uniaxial compression strength. Figure 2 compares the numerical relationship with the empirical relation of Salamon ( $\alpha=0.46, \beta=0.66$ and $\lambda=0.93$ ) and the linear relation $(\alpha=1, \beta=1$ and $\lambda=0.93)$. This comparison calls for the following remarks: the three relationships confirm that the increasing of $(\mathrm{W} / \mathrm{H})$ ratio increases the strength of the pillar; the pillar strength can be more or less than 1 according to the empirical approaches, however for the numerical approach, the pillar strength is greater or equal to the compression strength of the rock.

The strength of the pillar continues to increase according the "linear" approach, somewhat less for numerical approach, however it stabilizes around 1.10 for Salamon approach. Van der Merwe and Madden (2002) consider the relationship of Salamon and

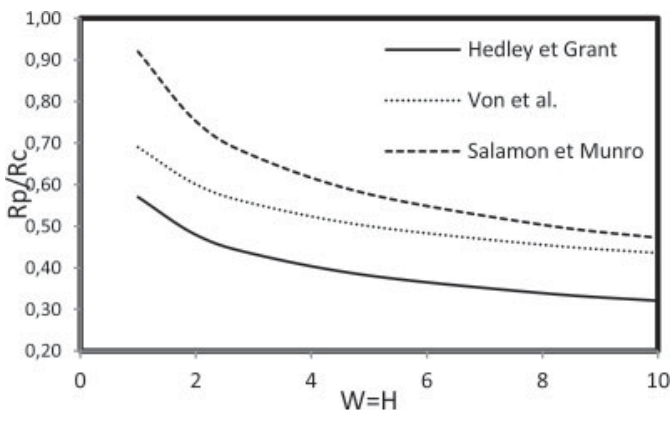

Figure 3. Evolution of pillar strength to the uniaxial compression strength for different values of $\mathrm{W}=\mathrm{H}(\mathrm{m}) \mathrm{W} / \mathrm{H}=1$ and different empirical equations (see table 1)

Munro tends to underestimate the strength of the large pillars and overestimate the resistance of small pillars. In fact, the numerical modelling with numerous parameters can certainly reflect the real behavior but due to time consuming issues, it may have limited their engineering application.

\subsection{Effect of pillar}

The influence of the width and height of the pillar to the same slenderness or equal to 1 was studied, therefore $\mathrm{W}=\mathrm{H}=1$ and for different values of $\mathrm{L}$ and $\mathrm{H}$. We used assumptions equations 1 to 3 (Table 1). Figure 3 shows the $\mathrm{Rp} / \mathrm{Rc}$ ratio. The large pillars are, according to these relationships, weaker than the small pillars and short. The relationship is not linear and the dimensions of the pillar regardless of its slenderness plays an important role in determining its strength.

\subsection{Variability of parameters}

The determination of parameters, $\lambda, \alpha$ and $\beta$ was made from data analysis. We do not have the variability of these parameters. To study the variability of such influence on the estimation of the strength of pillars, we adopted three parameters $(\alpha, \beta$ and $\lambda)$ with a normal distribution characterized by a mean value $(\mathrm{m})$ and standard deviation (s). The standard deviation is $10 \%$ of the average value. We analyzed this analysis for different $\mathrm{W} / \mathrm{H}$ ratio values $(\mathrm{H}=\mathrm{ct}$.).

Figure 4 presents three curves expressing the ratio estimating strength of the pillar relative to the uniaxial 


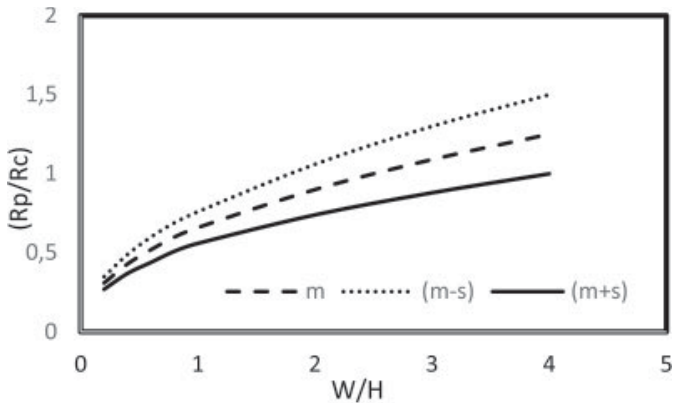

Figure 4. Evolution of pillar strength to the uniaxial compression strength for different values $\mathrm{W} / \mathrm{H}$, taking into account standard deviation $(\mathrm{s})=10 \%,(\mathrm{~m}=$ mean $)$.

compressive strength (mean, mean + standard deviation, mean-standard deviation). The standard deviation variation of $R p / R c$ is not linear, it varies between 12 and $20 \%$. For the design of an operating room and pillar area, it is safer to consider the lower limit (mean value minus the standard deviation).

This sensitivity parametric study can also be applied to all the variables in the empirical equation. The uncertainties on the pillar dimensions (width and height) and pillar strength lead to lower values (and higher) of the ratio $(\mathrm{Rp} / \mathrm{Rc})$ and can impact the design of pillars.

\subsection{Conclusion}

The methodology adopted and discussed herein takes into account the effect of scale on rock strength and pillar dimensions. The average stress of the pillar is determined by the method of the tributary area. Pillar strength is based on the simple compression standard test specimens and empirical coefficients related to the geometry of the pillars and can be determined by feedback analysis. The necessary data is limited to geometrical and geotechnical data from the underground mine. The uncertainty of the parameters can be considered thanks to sensitivity parametric studies.

\section{FEEDBACK OF THE CLAMART CHALK MINE}

The Clamart chalk mine was operated until 1880 by the method of abandoned room and pillar, (Al Heib et al., 2014). The disastrous collapse of the chalk mine of Clamart and Issy-les-Moulineaux, two bordering suburbs of Paris, on June 1, 1961 is one catastrophic example. The collapse of the Clamart mine caused the brutal subsidence of three hectares of ground surface and the destruction of a whole urban district, including residential buildings, several roads and sports facilities. Twenty-one people died and more than fifty people were injured.

The Clamart collapse was associated with two seismic events, 7 seconds between them, one at 10:30 am, when the soil subsided and loud noises had been heard, and the second collapse was recorded a halfhour later. Actually, the existing data of the events cannot be analysed today in order to obtain more information concerning the magnitude, the energy and the localization.

Two chalk levels were extracted separated by thin layer. In the southern part, the upper level has been exploited to the south and north with a different development scheme but in both cases very regular. The junction between the two zones takes place on a row of irregular and hybrid pillars. The geometric characteristics of the different areas are shown in Figure 5, they are also given in Table 2 . The ratio $(\mathrm{W} / \mathrm{H})$ is varied between 0.73 (ZNS1) and 1.4 (ZSS1).

The geometry of the pillars of the lower level is different from the upper level by its irregularity, that could result from an early cessation of mine operations.

To understand the origin of the collapse, we compare first the pillar stress $(<2 \mathrm{MPa}$, see table 2$)$ to laboratory uniaxial compression strength $(2 \mathrm{MPa})$, one can consider the pillars are very close to stability. We analyzed then the pillar stability using Salamon and Munro relation to calculate the strength of pillar taking into account the $(\mathrm{W} / \mathrm{H})$ ratio, considering that coal strength is the nearest strength of chalk. According to this choice, all areas of Clamart mine had a safety factor less than 1, except the area ZSI3. The ZNS1 area (upper level) would even have a value of 0.41 and note that all the pillars of the sector were very degraded and had probably been reinforced during the mining operation (of black lines in Fig. 5).

In light of this analysis, the mine could not be stable, including the top level. The collapse took place well after the mine operation and the value of the compressive strength of the chalk remains unknown during operation (short-term). The evaluation of the stability of the Clamart mine is essentially based on average values of the width, height, the compressive strength of the chalk and the coefficients $(\alpha, \beta$ and $\lambda)$. The compressive strength of the chalk was measured on ten samples; its value varies relatively little. We considered a normal distribution with a mean value of the resistance is $2 \mathrm{MPa}$ and a standard deviation of $0.2 \mathrm{MPa}$. The width of pillars is relatively constant, however the height of the pillars (galleries) is variable, we have measures particularly in the upper level. We calculated, for a normal distribution, the average height and the standard deviation are $6.45 \mathrm{~m}$ and $0.97 \mathrm{~m}$ respectively. From these data we calculated the pillar strength and the maximal and minimal values of $\mathrm{R}_{p} / \mathrm{R}_{c}$. according to several hypotheses shown in Table 3 .

The arbitrary choice of coefficients $(\alpha, \beta$ and $\lambda)$ and the uncertainty or variability of geometric parameters gives an average pillar strength of the order of 1.34 MPa instead of 1.23 MPa (see Table 3) and a standard deviation of between $0.23 \mathrm{MPa}$ and $0.32 \mathrm{MPa}$.

The minimum and maximum ratios of $\mathrm{Rp} / \mathrm{Rc}$, calculated basing on the statistical variation, are respectively 0.8 and 0.54 . This approach is used to evaluate the stability of pillars for a homogeneous area in which the dimensions are not perfectly identical, and the 

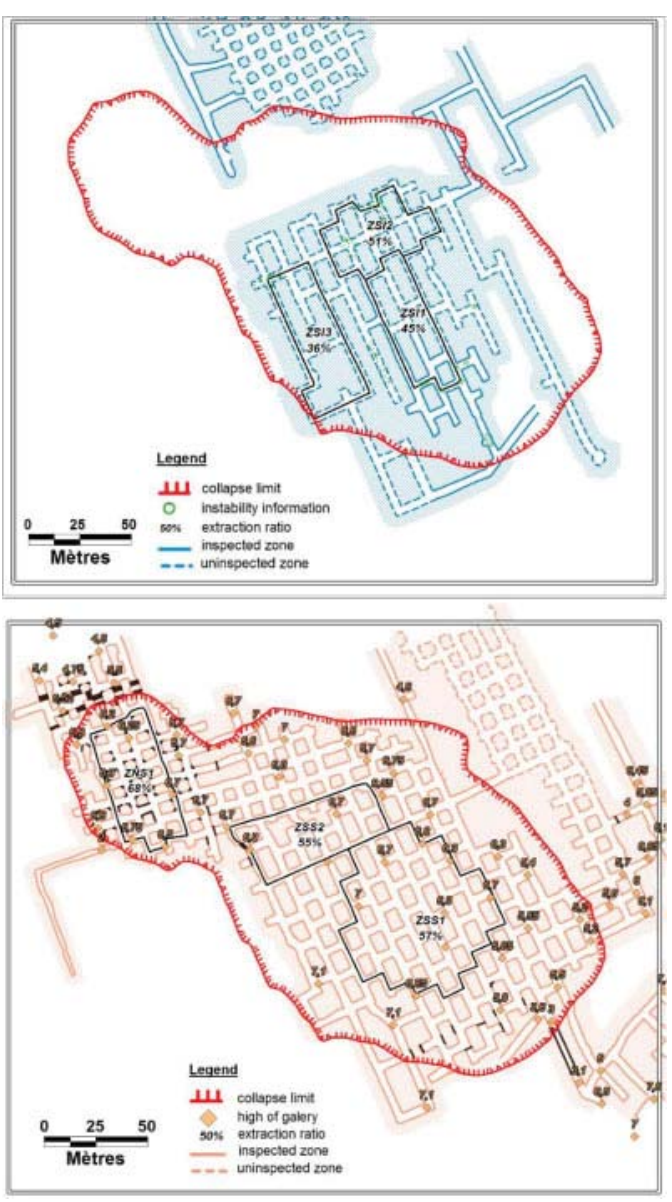

Figure 5. Clamart chalk mine, collapse zone in upper and down levels.

Table 2. Different parameter values to estimate the pillar strength.

\begin{tabular}{lllllllll}
\hline & & & & & & & & \multicolumn{2}{c}{$\begin{array}{l}\mathrm{SF}= \\
\text { Zone }\end{array}$} & $\mathrm{m}$ & $\mathrm{m}$ & $\mathrm{R}$ & $\mathrm{H}$ & $\mathrm{W} / \mathrm{H}$ & $\mathrm{Rp} / \mathrm{R}_{C}$ & $\sigma \mathrm{p}$ & $\mathrm{Rp} / \sigma_{P}$ \\
\cline { 2 - 9 } & & & & & & $\mathrm{MPa}$ & \\
\hline ZSS1 & 42 & 7 & 57 & 7 & 1 & 0.63 & 1.95 & 0.65 \\
ZSS2 & & - & 55 & 7 & & & 1.87 & 0.67 \\
ZNS1 & & 5 & 68 & 6.8 & 0.73 & 0.55 & 2.63 & 0.41 \\
ZSI1 & 52 & 7 & 45 & 5 & 1.4 & 0.85 & 1.75 & 0.97 \\
ZSI2 & & & 51 & 5 & 1.4 & & 1.96 & 0.86 \\
ZSI3 & & & 36 & 5 & 1.4 & & 1.5 & 1.26 \\
\hline
\end{tabular}

D: depth, W: pillar width, H: pillar height, E: extraction ratio.

rock strength is variable some pillars have very low strengths because of their dimensions and also their resistance. The collapse certainly started at pillars with very low safety factor. In addition, the presence of competent limestone bed in the upper roof had played an essential role on the stability during mining operation (Al Heib et al., 2014).
Table 3. Different parameter values to estimate the pillar strength.

\begin{tabular}{|c|c|c|c|c|c|}
\hline Simul & $\begin{array}{l}\mathrm{R}_{\mathrm{c}} \\
(\mathrm{m}, \mathrm{s})\end{array}$ & $\begin{array}{l}\mathrm{W} \\
(\mathrm{m}, \mathrm{s})\end{array}$ & $\begin{array}{l}\mathrm{H} \\
(\mathrm{m}, \mathrm{s})\end{array}$ & $\begin{array}{l}\mathrm{R}_{\mathrm{p}} \\
(\mathrm{m}, \mathrm{s})\end{array}$ & $\begin{array}{l}\mathrm{R}_{\mathrm{p}} / R_{\mathrm{c}} \\
(\max , \min )\end{array}$ \\
\hline & $\mathrm{MPa}$ & $\mathrm{m}$ & $\mathrm{m}$ & $\mathrm{MPa}$ & \\
\hline (1) & $(2,0)$ & $(7,0)$ & $(6$. & (1. & $(0$. \\
\hline (2) & $(2,0.2)$ & $(7,0.1)$ & $(6.45,0.97)$ & $(1.36,0.32)$ & $(0,8,0.58)$ \\
\hline (3) & $(2,0.2)$ & $(7,0.7)$ & $(6.45,0.97)$ & $(1.36,0.23)$ & $0,72,0,62$ \\
\hline
\end{tabular}

It is true that the accumulation of variations on the coefficients $(\alpha, \beta$ and $\lambda)$, the uniaxial compression strength and the dimensions of the pillars is a strong assumption and can affect the design results. Nevertheless, it encourages us for the purpose of stability assessment to determine the most accurate way these coefficients $(\alpha, \beta$ and $\lambda)$ and know the geometric variability of the pillars in the area in question.

\section{STABILITY OF CHALK MINES (MEUDON)}

In the zone of Clamart, there are several underground mines, comparable to Clamart collapsed mine. The Meudon chalk mines were operated on two levels (sometimes more). The mine depth varies between 20 and $50 \mathrm{~m}$. The mining method is room and pillar abandoned. The pillars are generally square in shape and variable dimensions according to the adopted extraction ratio. This extraction rate varies between 30 and $70 \%$. Former mechanical tests were performed to determine the uniaxial compression strength of the chalk, the range of variation is between 1.8 and $2.45 \mathrm{MPa}$. In addition, 34 cases were analyzed including 15 cases of collapses in nearby areas of similar configurations (from 1843-1961). The objective is to distinguish between stable and collapsed abandoned chalk mines.

We performed an estimation of the safety factor based on the collected data in particular on the geometry of the chalk mines. We considered an average uniaxial compression strength of $2.25 \mathrm{MPa}$; while the lowest strength is $1.8 \mathrm{MPa}$, an average height of $6 \mathrm{~m}$ pillars (varies between 7 and $5 \mathrm{~m}$ ). The average strength of the pillars is calculated based on the relationship of Salamon and Munro. Figure 6 shows the histogram of the safety factor for underground chalk mines, the blue columns correspond to stable mines (until now) and red for collapsed chalk mines. The average safety factor for stable mines is equals to 1.2. The average value of collapsed mines safety factor is 0.76 , so half the mines regarded to be stable today. More precise analysis is recommended for the mines with an average safety factor is less than 1 and still stable.

If one analyzes collapsed over time, Figure 6 shows that the most recent collapsed mines have generally higher a safety factor than the oldest collapses. This 


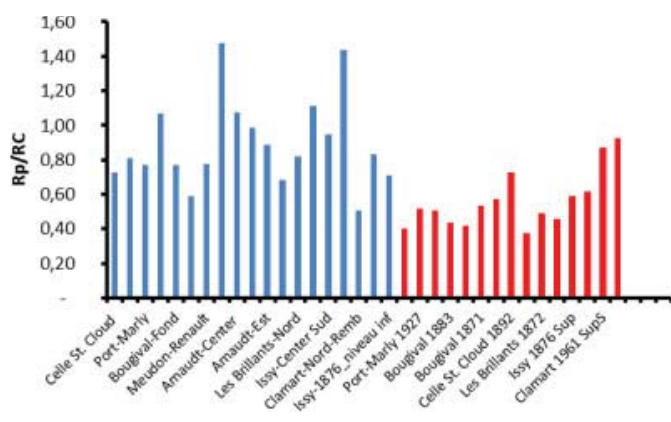

Figure 6. Safety factor for 34 underground chalk mines 15 (red and left) are collapse chalk mines.

could be explained by two reasons: the first is the reduction of the uniaxial compressive strength over time and the second reason is the limestone bed role The limestone bed has a role important on the stability. It can reduce the load up to its rupture. The role of the stiff bed has been discussed in the case of mass collapses (Al Heib et al., 2014).

\section{CONCLUSION}

The goal of the study is to discuss the analysis of the stability of pillar. The method of the tributary area is dependent on the choice of parameters and the feedback. We discussed here the pillar strength where two effects should be taken into account: the scale effect $(\lambda<1)$ and the pillar geometry. Empirical relationships have been used to design the pillar. We have shown the importance of geometry and $\mathrm{W} / \mathrm{H}$ ratio. The empirical relationships converge to almost the same results despite the difference between the coefficients of these empirical relationships.

The application of these relationships can help to explain the collapse of Clamart mine. The pillars of Clamart are unstable $(\mathrm{SF}<1)$ due to the geometry of pillars and the extraction ratio.

In conclusion, the design or back-analysis of room and pillar stability must take into account the pillar stress ratio and pillar of strength. The stress can be determined using the method of the tributary area and the pillar strength by using the empirical relationships taking into account the scale effect $(\lambda)$ and the effect of the geometry $(\alpha$ and $\beta$ ). Sophisticated tools are useful to understand the rock mass and mines (pillars) behavior.

\section{REFERENCES}

Al Heib M. Duval C. Theoleyre F. Watelet J.M. Gombert P. 2014. Analysis of the historical collapse of an abandoned underground chalk mine in 1961 in Clamart (Paris, France). Bull Eng Geol Environ DOI 10.1007/s10064014-0677-6.

Bieniawski, ZT. 1968, The effect of specimen size on compressive strength of coal. Int. J. Rock Mech. Min. Sci. Pergamon Press. 5. 325-335.

Esterhuizen G.S., Dolinar D. and Ellenberger J.L. 2011. Pillar strength and design methodology for stone mines in the United States. Int. J. Rock Mech. Min. Sci. 48, 42-50.

Hedley DGF, Grant F. 1972. Stope and pillar design for the Elliot Lake Uranium Mines. Bull Can Inst Min Metall: $37-44$.

Laouafa F. 2004. Modélisations des exploitations de sel. INERIS DRS-04-56168/R01.

Mark C. 2006. The evolution of intelligent coal pillar design 1981-2006, Proceedings, 25 International Conference on Ground Control in Mining, Morgantown, West Virginia, 325-334.

Martin C.D. and Maybee W.G. 2000. The strength of the hardrock pillars. Int. J. Rock Mech. Min. Sci 37 1239-1246.

Oyanguren R. Lain R. 2003, La stabilité des mines de fer de la région de Bilbao (Espagne). Après-mines, Nancy, France.

Salamon MDG, Munro AH. 1967. A study of the strength of coal pillars. J S Afr Inst Min Metall; 55-67.

Van der Merwe N. Madden B.J. 2002. Rock Engineering for underground coal mining Technical Editor: Paul Buddery Strata Engineering (Australia) Ltd.

Von Kimmelmann MR, Hyde B, Madgwick RJ. 1984. The use of the computer applications at BCL Limited in planning pillar extraction and design of mining layouts. In Brown ET, Hudson JA, editors. Proceedings of ISRM Symposium: Design and Performance of Underground excavations. London, British Geotechnical society, 53-63. 